\section{Germplasm enhancement and cultivar development: The need for sustainable breeding}

\section{Marcelo J Carena}

Abstract: Farmers need sustainable cultivars to increase food supply and value with less production land, animals, and inputs. Next generation plant and animal breeders face climate change adaptation and mitigation challenges. These challenges need to be addressed with opportunities for significant reduction of environmental impact developing cultivars less addicted to fertilizers and soil moisture needs. Sustainable breeding can help balance agriculture with the environment. Sustainable breeders need to integrate long-term pre-breeding activities with cultivar development efforts providing farmers options to comply with environmental regulations. Good choice of germplasm is still the most important decision. The most sophisticated tools will have limited success if poor choices of germplasm are made. Seed companies need capable breeders developing the next generation of sustainable cultivars while public institutions need to mentor sustainable breeders capable to not only broadening and improving unique germplasm but also developing new cultivars carrying desirable traits. Graduates mentored in breeding programs integrating these needs will be selected for industry jobs without need for re-training. Sustainable breeders will need to operate in new breeding centers located in strategic environments for faster genetic improvement ahead of climate changes. Key factors for developing useful and unique sustainable cultivars will be the adaptation of exotic germplasm and the maximization of its genetic improvement before cultivar development through public and private partnerships. Inbreeding, genetic divergence, and reciprocal recurrent selection programs will continue to be essential to purify cultivars and exploit heterosis in economically important species.

Keywords: Sustainable breeding, pre-breeding, cultivar development, genetic diversity, addiction to water and nitrogen.

\section{INTRODUCTION}

Agriculture is responsible for a significant percentage of the total greenhouse gas emissions and global leaders are considering the inclusion of agriculture in emission budgets. Sustainable strategies and government requests will focus on reduced use of water, fertilizer, and pesticides on farms to adapt to climate changes and reduce environmental footprint. But who will develop the next generation of cultivars with reduced fertilizer requirements and better performance under soil moisture deficit? (Carena 2021b).

Farmers are often blamed for the impact their farms have on the environment. But plant breeders develop the cultivars farmers plant on their farms. These cultivars are genetically narrow and are currently addicted to water and fertilizers due to being bred under high inputs. In addition, farmers need pesticides to
Crop Breeding and Applied Biotechnology 21(S): e385621S4, 2021 Brazilian Society of Plant Breeding. Printed in Brazil http://dx.doi.org/10.1590/198470332021v21Sa17

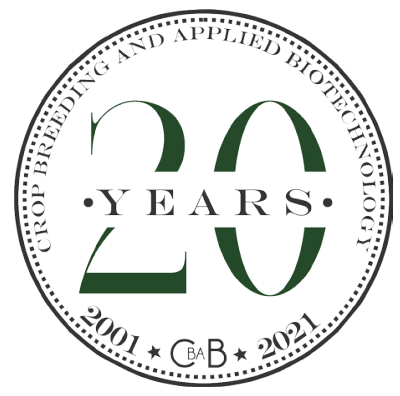

$*$ Corresponding author:
E-mail: marcelo.carena@agresearch.co.nz (iD) ORCID: 0000-0002-4021-6282

Received: 07 June 2021 Accepted: 12 June 2021 Published: 06 July 2021

${ }^{1}$ AgResearch Ltd. Grasslands Research Centre, Palmerston North 4442, New Zealand 
protect their cultivars from pests and diseases. Thus, farmers have no options to reduce their environmental footprint unless they consider efforts to certify their farms as organic. Even then, minimal efforts have been devoted to developing cultivars under organic or sustainable conditions.

Plant breeding is a science of evolution (Hallauer et al. 2010) and has mainly been associated with profitable cultivar development, often without consideration of its ecological footprint (Wackernagel and Rees 1995). Against all odds, plant breeders have been able to accelerate evolution on their favor and produce more in less area. However, in many cases, plant breeding means have not been sustainable, contributing directly or indirectly to agriculture greenhouse emissions and climate change. Diverse plant genetic resources and effective plant breeding techniques can provide sustainable cultivars while co-existing with profitable businesses.

Plant breeding has been identified as the source of food and the strategy over hunger. But plant breeding and human population are only two factors in the puzzle of world challenges and opportunities. Plant breeding alone cannot 'feed the world' sustainably without economic and policy changes in worldwide food production, distribution, consumption, and waste systems as well as in world population distribution patterns.

The effects of COVID-19 on the economy provide an opportunity to strategically design the future agricultural sector focused on not only profits but also on a healthy population in equilibrium with the environment. World plant breeders, with the support of national leadership and international centers, have the task of developing the next generation of sustainable cultivars and cost-effective breeding methodologies that will facilitate successful and sustainable results for the common good of all world citizens and their environments. The pressure of climate change needs innovative solutions for challenges ahead, not necessarily cutting edge.

\section{NEXT GENERATION BREEDING}

The future tempts us to think about digital agricultural and modern genetic technologies. But tools do not provide long-term goals. Technology can help achieve some breeding goals, but breeders need to be prepared to screen these technologies according to trait complexity and focus on the big picture. Genomes have been sequenced and information in plant genetics has significantly expanded. However, the limiting factor for genetic improvement remains the same. There is no point in utilizing the best technology or breeding technique with poor germplasm. The most sophisticated technologies carrying genetic information will have limited success if poor choices of germplasm are made. Biotechnology continues to be an important addition to the breeding process for single-gene traits while systematic breeding efforts continue to be key for improving economically important traits of quantitative inheritance. Efforts in identifying unique alleles from unique germplasm will be essential to improve traits rather than sequencing the most known genotypes.

Lowering fertilizer and water demands for farmers has not been a high priority in the scientific community (Hallauer et al. 2010, Davies et al. 2020). Sustainable plant breeding is a viable scientific alternative to maintain enough food supply under the environmental challenges facing our planet (Carena 2017). It includes responsible breeding with the most efficient and wise use of resources, genetic diversity, maximizing conservation, and minimizing waste. It can work toward developing the next generation of cultivars while still providing farmers options to adapt to new environmental requirements. Once agriculture is transformed it can still drive prosperity increasing sustainability through enhanced biodiversity. Sustainable plant breeding is about preventing future epidemics and adapting to climate changes while reducing farm costs and impacts to the environment.

\section{THE MAIZE EXAMPLE}

Plant breeding has assisted the agricultural sector with the production of more food per hectare. One of the most successful plant breeding examples is maize. Grain yield increases shown in Figure 1 reflect the rapid acceptance in

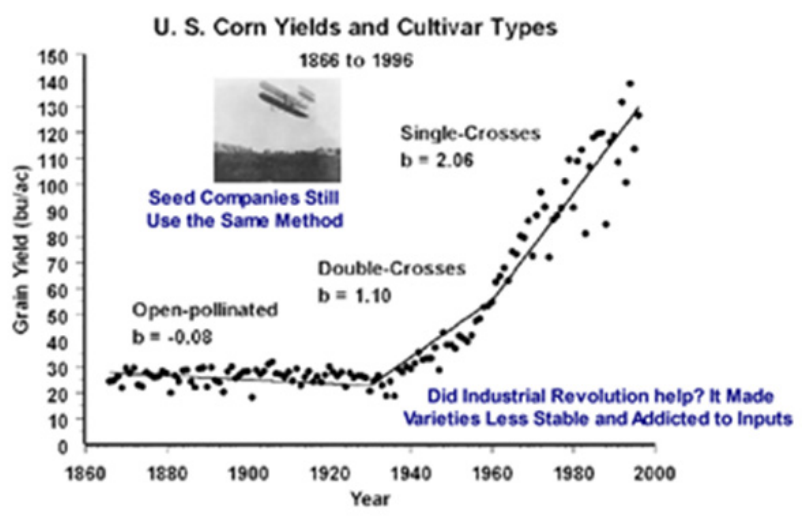

Figure 1. U.S. average maize yields from 1865 to 2000. 
the use of hybrid seed, changes in types of hybrids grown, and improvements made in crop genetics and husbandry (Hallauer et al. 2010) during the industrial revolution. Similar increases would have been possible if similar efforts on extensive population improvement programs were present across decades.

Modern plant cultivars became genetically narrow, less stable, susceptible to biotic and abiotic stresses, and addicted to inputs. In maize, grain yield of single-cross hybrids has increased with the use of high plant densities (Troyer and Rosenbrook 1983, Mansfield and Mumm 2014). Most maize breeding programs have increased selection under high plant densities over time to develop cultivars with better tolerance to high plant densities (Figure 2). One of the undesirable consequences, however, was that more seed was needed for breeding and production purposes. Since seed is sold by the unit, it has also increased overall seed costs to farmers.

Carena and Cross (2003) and Hyrkas and Carena (2005) have identified density independent maize populations that could be bred under low plant densities to reduce seed production needs in breeding programs and annual seed costs to industry and farmers. However, millions of taxpayer dollars are utilized annually to conducting research including cultivars bred under ideal environmental conditions without analyzing genotype $x$ input interactions. Edwards (2016) showed an example of evaluating highdensity bred maize cultivars under different plant density levels. In a similar way, farmers currently have no options to reduce fertilizer applications because the market mostly offers cultivars bred under high fertilizer levels (Figure 3). Several $\mathrm{N}$ levels are used in such research trials to recommend cultivars with better nitrogen use efficiency. But researchers need to consider first if cultivars have been bred under only one level of N (Figure 4). Selection under different $\mathrm{N}$ and plant density levels in North Dakota Stiff Stalk (NDSS), North Dakota Lancaster (NDL), and EarlyGEM populations has already shown significant interactions confirming the need to breeding under low $\mathrm{N}$ levels too. Further research is needed to identify genotypes under different input needs. Breeding under dry and low input environments will aid in developing the next generation of sustainable cultivars. Figure 5 shows divergent population improvement efforts for inputs, plant density, and abiotic stress tolerance in strategic environments.

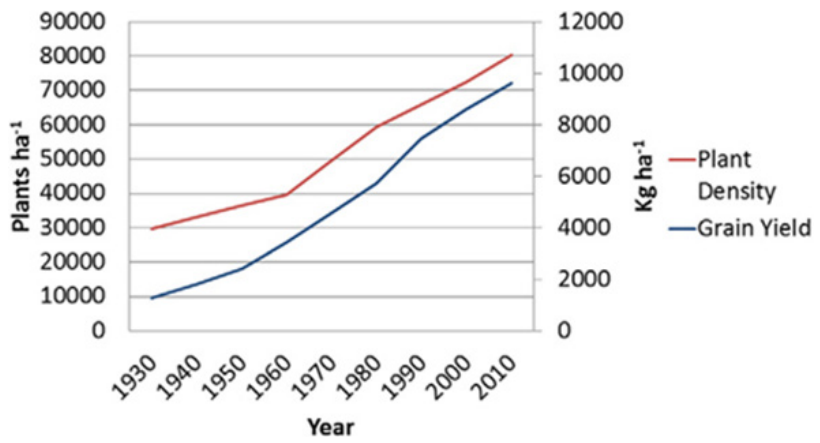

Figure 2. Plant density tolerance in US maize germplasm (adapted from Mansfield and Mumm 2014).

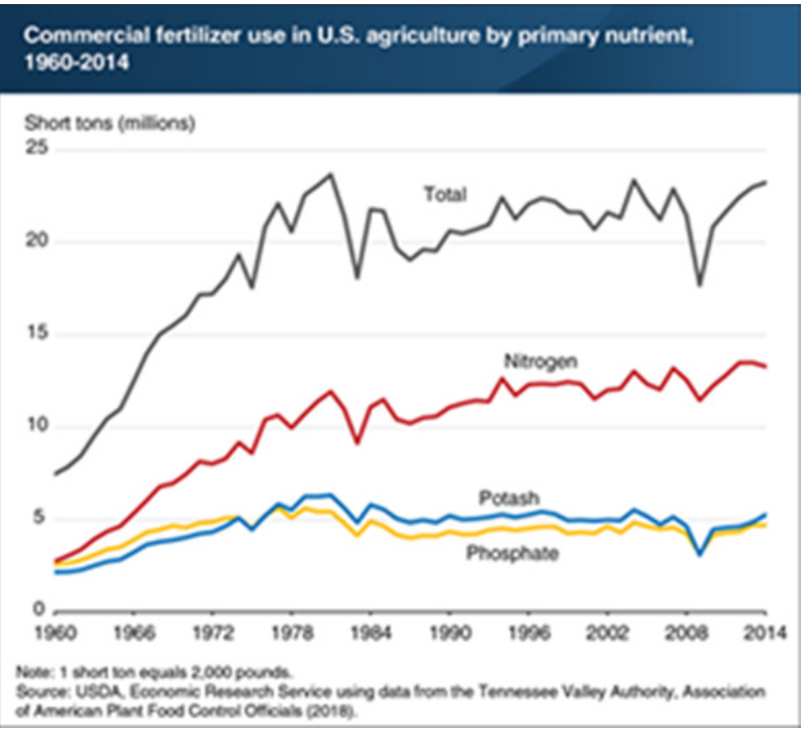

Figure 3. Sustainable breeders face current and future climate and environmental footprint challenges.

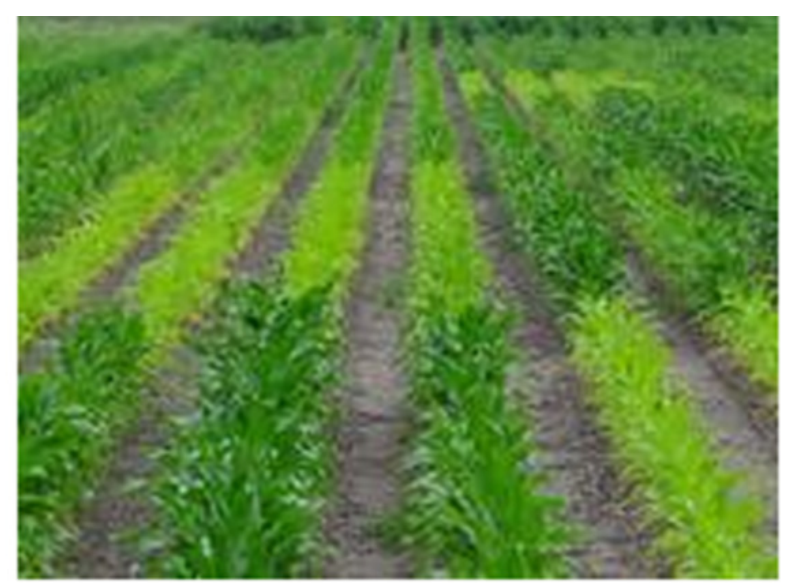

Figure 4. Maize breeding nursery developing low $\mathrm{N}$ cultivars (adapted from Carena 2021c). 


\section{GERMPLASM ENHANCEMENT AND CULTIVAR DEVELOPMENT}

Preserving and utilizing genetic diversity: Achieving desirable trait combinations

Genetic diversity is a requirement for sustainable agrifood production. Plant breeding needs genetic diversity to be sustainable. Large samples of adapted germplasm maximize desirable trait combinations often negatively correlated in genetically narrow germplasm (Figure 6). Therefore, investing and maintaining local short- and long-term cold storage conditions is essential for future generations. Developing outstanding sustainable low-cost and low-risk cultivars for farmers rely on breeding programs utilizing stored genetic diversity, especially when intellectual property limits the improvement of industry products for providing better products to farmers (Carena 2013a, Bari et al. 2016).

Genetic diversity is essential for obtaining significant genetic gains in economically and environmentally important traits. These gains will make sustainable impact if the incorporation of novel germplasm is conducted in breeding programs integrating germplasm improvement with cultivar development. But these programs have been scarce due to long-term needed to adapt and maximize genetic improvement of elite diverse germplasm. These unique programs will provide genetic materials carrying unique and diverse alleles, increasing sample sizes limited by genome sequencing programs and core collections, and improving prediction of breeding values for realized genomic selection. But even more important, the presence of unique genes have positive implications for farmers and industry in the long run. They provide a unique combination of agronomic, environmental, and quality traits not available in industry cultivars, serving as the future sources of elite cultivars carrying diverse genetics.

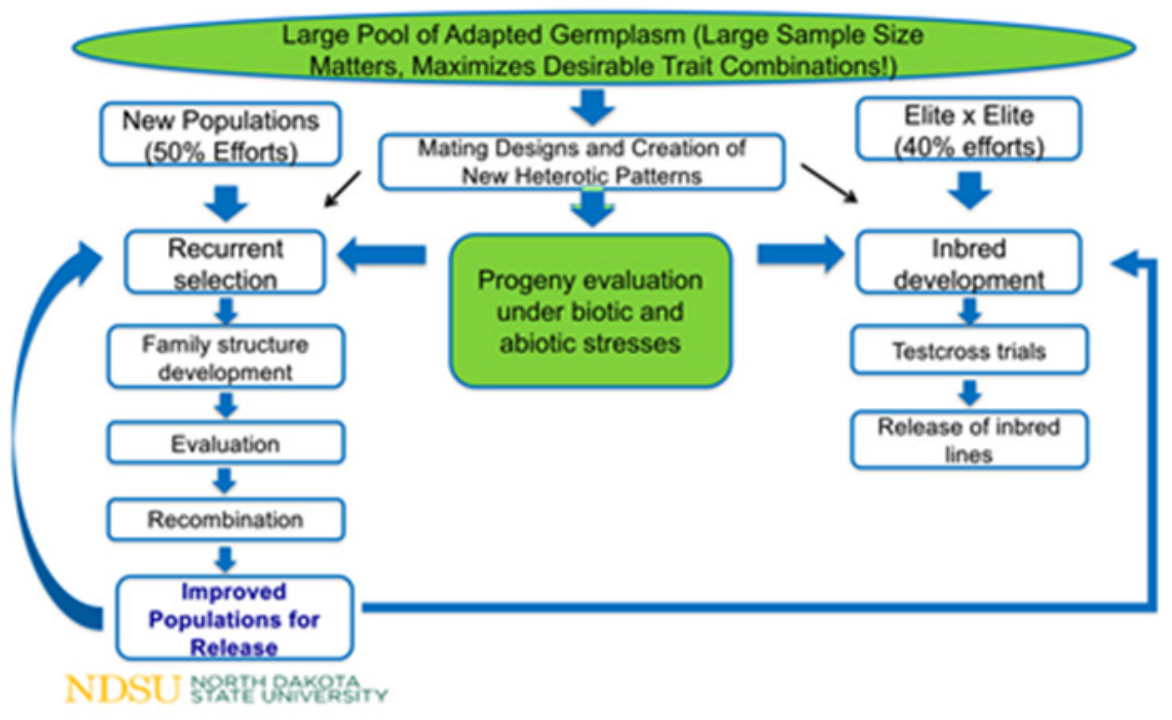

Figure 6. Maize pre-breeding and cultivar development efforts conducted during 1999-2017. 
Choosing the right germplasm and methodology in addition to utilizing large samples of genetically broad-based germplasm is a requirement for multi-trait selection. With enough genetic diversity high-yielding maize cultivars with lowest grain moisture at harvest have been identified, a sustainable combination that reduced risk for northern U.S. hybrids. Diverse products have not only showed tolerance to climate change with better abiotic and disease resistance with less input requirements but also have successfully impacted the sustainability and stability of agricultural production (Carena 2013a, b, c, 2017).

\section{Pre-Breeding I: Acquisition of germplasm}

Pre-breeding includes the introduction, adaptation, evaluation, and improvement of germplasm resources for use in breeding programs (Hallauer and Carena 2009, 2014).

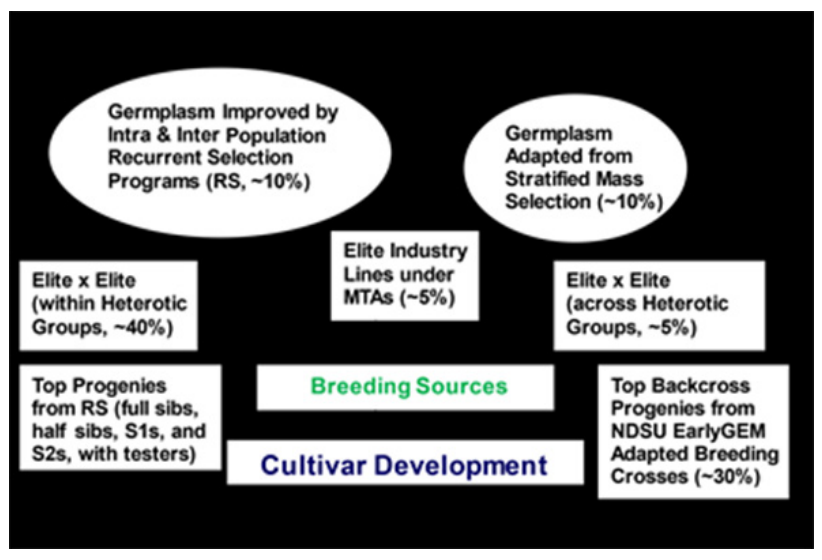

Figure 7. Pre-breeding sources utilized for cultivar development (adapted from Carena et al 2009b).

It is a long-term investment. Pre-breeding develops germplasm resources that are either directly or indirectly used to develop new cultivars. Figure 7 shows approximate percentages for germplasm sources utilized for cultivar development during 18 years in North Dakota. Some cultivars are still being commercialized today.

Adequate choice of germplasm and pre-breeding are essential to increase useful genetic diversity and develop unique cultivars. If genes for drought tolerance or for nitrogen use efficiency are not present, the efforts of the breeder will be futile regardless of experimental techniques or latest genomic technologies available.

The use and improvement of diverse genetic resources is not often a priority within private breeding programs. Public breeding programs provide genetic diversity in reserve (Duvick 1984), breeding creativity, and an insurance against genetic vulnerability through continuous genetic improvement of elite genetically broad-based breeding populations (Carena and Wicks III 2006). Exotic germplasm includes genetic materials not presently adapted to target environments lacking immediate usefulness without adaptation and improvement (Carena and Hallauer 2001a). Commercial cultivars without improved exotic genetic materials are vulnerable to pest and disease epidemics.

The small percentage of germplasm used across species is a consequence of insufficient germplasm evaluation and further improvement. Prevention is essential to avoid major national economic losses. The 1970s Southern Corn Leaf Blight epidemic in the USA caused billions of dollars in losses and a warning call from the National Academy of Sciences. The USDA supported the creation of a consortium of public and private organizations to increase the genetic diversity of industry hybrids through the Germplasm Enhancement Maize (GEM). Even with LAMP, NCSU, and GEM efforts (Sevilla and Salhuana 1997, Goodman 1999, Pollak 2003, Carena 2002, Carena and Sharma 2016) the excessive use of ex-PVP genetic materials (Bari et al. 2016) has increased the number of genetically narrow identical hybrids with different single-gene transgenic events.

\section{Pre-Breeding II: Adaptation of germplasm}

The adaptation of unique tropical and temperate germplasm provides a unique combination of traits not available in industry cultivars. Exotic populations with high starting trait means are the future sources of elite cultivars carrying diverse genetics to adapt to climate change and lower environmental footprint. Long-term breeding programs across countries have been essential to improve trait means. Two have been the strategies of the North Dakota maize breeding program to adapt new germplasm:

a) (Early x Late) x Early backcrosses through the EarlyGEM (Carena 2003, Sharma and Carena 2012) and the EarlyQPM and EarlyQPMF (Laude and Carena 2015, Carena and Dong 2017, Carena 2021a) programs. Numerous competitive releases and experimental materials of short-season $\mathrm{BC}_{1}: \mathrm{S}_{1}$ populations and inbred lines carrying diverse percentages of tropical and late temperate germplasm from Latin America and southern USA should be available from the Department of Plant Sciences and the Research and Technology Park at North Dakota State University (NDSU). Details of these 
programs are available in Carena (2017) and elsewhere. The EarlyGEM program is successfully being duplicated in China to reduce the vulnerability of maize production and it is being used as model to other species in New Zealand to adapt forages to climate change and lower inputs (Davies et al. 2020).

b) Stratified mass selection through the EarlyTROP program (Carena 2021a). Mass selection has successfully been utilized to adapt exotic germplasm across latitudes (Hallauer 1999, Carena et al. 2008, Hallauer and Carena 2016). When properly conducted for genetically simple traits, it has maximum efficiency and success across genotypes without exceptions. Stratified mass selection (Gardner 1961) for earliness, as primary selection target, has shown to be a cost-effective methodology to successfully adapt long-season maize to early maturing regions at $\$ 2,000$ per variety (Carena 2017, 2021a).

New synthetic varieties and populations per se have been created through these programs and released for commercial production or in hybrid combinations.

\section{Pre-Breeding III: Maximizing genetic improvement of adapted germplasm}

If enough genetic diversity is gathered in breeding programs through local and adapted germplasm, then breeders will be able to maximize genetic gain sustainably. Local sources of germplasm do not need additional time for adaptation and can directly be incorporated into pre-breeding improvement programs.

Genetic improvement of populations is often performed by recurrent selection methods (Figure 8). These are designed to improve traits with low heritability in the long-term. The goals of recurrent selection are to improve multiple-trait multi-environment means through selection indices increasing the frequency of favorable alleles and, as important, to maintain genetic variability for further selection. Intra- and inter-population recurrent selection programs (Hallauer et al. 2010, Hallauer and Carena 2013) have been successful to improve quantitative traits with the utilization of progenies. It takes about two to four years per cycle of progeny selection to improve economically important traits like yield. However, one year per cycle can be achieved for other genetically complex traits when selecting among progenies before flowering time. In those cases, evaluation and recombination can be done in the same season like in the intra-diallel initiative for cold tolerance (Sezegen and Carena 2009) or in resistance to pests when inoculation and infection can be conducted in screening nurseries before flowering time. Genomic selection still has the potential to aid in these programs, but caution should be considered when selecting within progenies. The recombination of a large effective population size is essential to guarantee future genetic gain progress avoiding inbreeding depression. In addition to improving years per cycle with the utilization of winter nurseries, knowledge of genetic structure of populations has also been helpful when selecting breeding methodologies for certain populations (Figure 9).

There are critical decisions in every recurrent selection program. Choice of germplasm continues to be the most important decision. Breeders can review literature, visit stations, and choose populations with high means of desired traits and adequate genetic variability. Producing

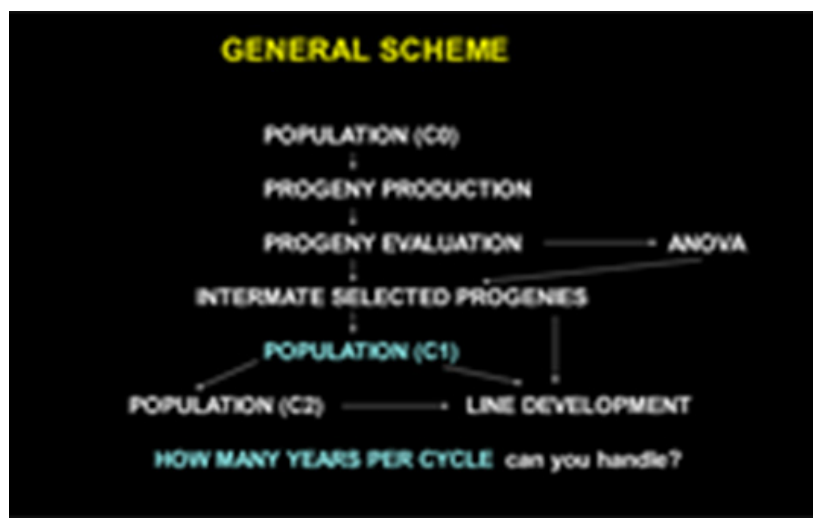

Figure 8. Scheme for intra-population recurrent selection.

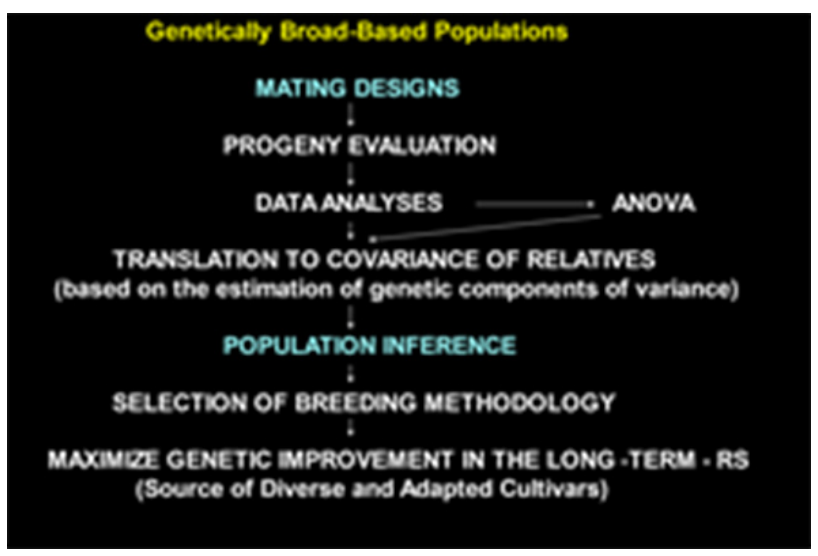

Figure 9. Selecting breeding methodologies based on population structure. 
progenies is the next step. Choice of progenies depends on the species, trait, and objectives and Figure 9 shows how mating designs can help. The Evaluation of genotypes for selection is the third critical decision that should try to minimize error with extensive testing providing as much information as possible. Finally, Intermating a large sample of selected progenies is crucial to conduct it in a representative way. In maize, diallel mating designs, topcross isolations, and the bulk-entry method have been useful. Two or three bulks of equal amounts of seeds per ear selected will be sufficient for distribution, selection, and evaluation.

Observed genetic gain will never be equal to predicted genetic gain. Prediction strategies can be used if they can complement extensive testing to reduce the importance genotype by environment interactions. Therefore, conducting accurate routine selection response evaluation experiments becomes important. Maintaining viable seed with large population sizes and producing quality seed before evaluation are needed for each selection cycle.

Open-pollinated species can utilize maize breeding techniques exploiting heterosis (Carena 2021d). The exploitation of heterosis via forage semi-hybrids or maize population hybrids (Carena 2005) can maximize genetic gain of genetically complex traits. Heterosis can maximize genetic gain in complex traits such as drought and can be inferred from heterotic patterns (Hallauer and Carena 2009). It has played significant roles in the adaptation to drought and other stress conditions (Tollenaar et al. 2004, Carena et al. 2009b). A heterotic pattern is a cross between known genotypes expressing a high level of heterosis (Carena and Hallauer 2001b). Development of successful population hybrids is based on the identification and utilization of heterotic groups and patterns (Hallauer et al. 2010). The exploitation of genetic diversity and heterosis through reciprocal recurrent selection programs will provide the next generation of sustainable cultivars with drought tolerance for the milk and meat industries.

\section{Pre-Breeding IV: Exploiting strategic environments}

Farmers in marginal environments have not been well served by industry. High yielding cultivars are often not stable due to breeding efforts focus on ideal environmental conditions. The lack of stable cultivars reduces the options for farmers in marginal conditions and those that will be affected by climate changes in the future.

The market often does not reach farms located in challenging locations, but these locations can serve as strategic environments for breeding sustainable cultivars. Progressive farmers have been ready to adapt to climate change for a long time. They have provided in-kind land as leases to visionary researchers. For instance, the utilization of controlled winter nursery environments for abiotic stresses has been a solution to developing cold and drought tolerant maize products (Carena et al. 2009a).

While farmers in all regions are being asked to mitigate their environmental footprint, they are unable to access market cultivar options to address their sustainability challenges. There is a lack of awareness of this missing link between industry and farmers. The seed industry is responsible for providing sustainable options to farmers but has historically focused on developing cultivars with high fertilizer and water inputs. Lowering fertilizer, irrigation, and seed costs to farmers and ranchers has not been public or private priorities but would be desirable for sustainable breeding efforts. National funded initiatives could generate scientific and commercial solutions leading to climate-resilient cultivars being available to farmers.

Countries have traditionally located their public and private breeding programs in most favorable production areas (Figure 10). Sustainable breeding programs, however, need to take advantage of challenging environments. Although non-stress environments are desirable to farmer fields, extension agronomist trials, and seed production needs, most breeding work focuses on screening thousands of genetic materials discarding weak genotypes. Thus, breeders need strategic environments to separate strong from weak genotypes under extreme conditions to direct evolution faster and more effective. This is essential if breeding is to be effective and agriculture sustainable.

Opportunities to utilize strategic environments have often been neglected by simply breeding or only testing under non-marginal conditions. Thus, adaptation of genotypes has been slower and stability of commercial cultivars low. Breeding programs utilizing challenging environmental conditions for sustainable cultivar development could also serve farmers regardless of industry regional investment strategies.

Sustainable breeders should be able to move their breeding stations out of their places of comfort to exploit the 


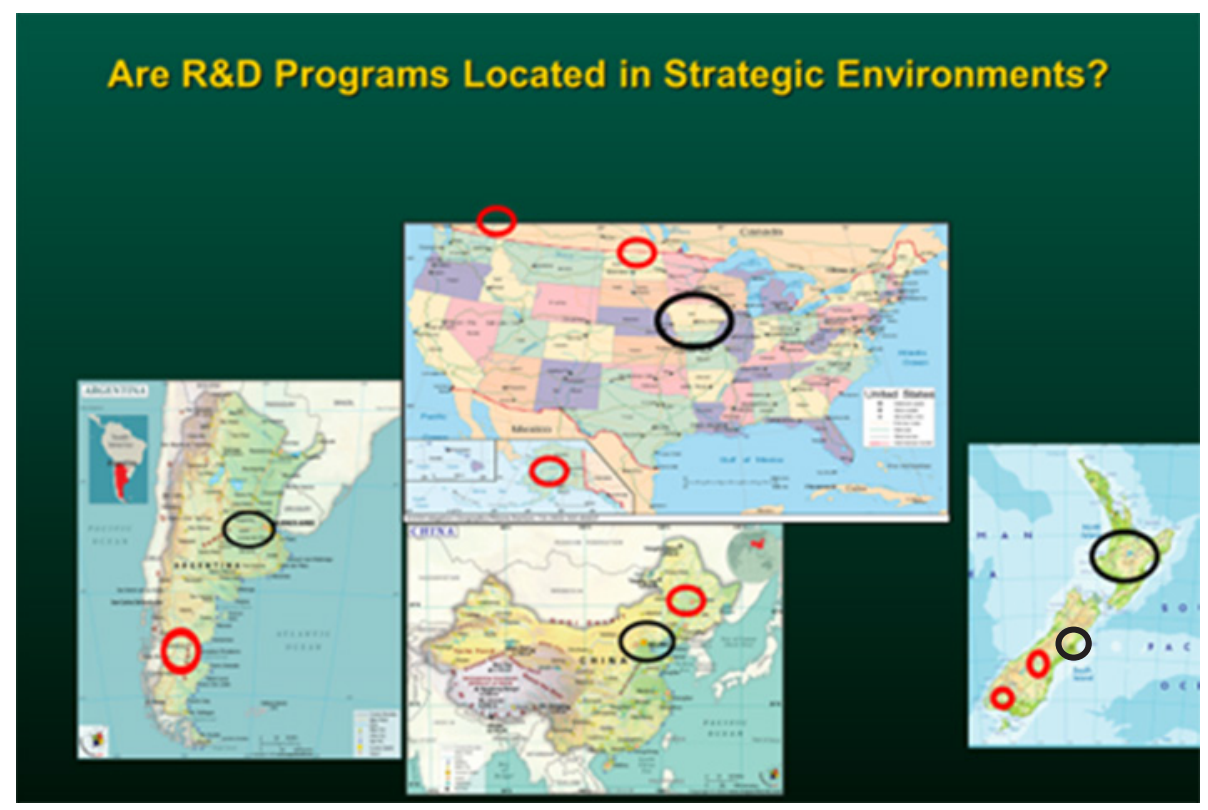

Figure 10. Current (black circles) and future strategic (red circles) breeding program locations (adapted from Carena 2021c).

worst possible environmental conditions. Environmental stresses can be utilized under controlled conditions in winter nurseries for faster genetic gain and additional screening while extensive testing continues to be under stressed and ideal conditions in target environments. Scientists must include as many individuals (for genetically simple traits) or progenies (for genetically complex traits) as possible. Experiments should be conducted under the most accurate uniform screening protocols, giving all genetic materials an equal chance to show their strengths and weaknesses. Genetic resources need to withstand any stress the breeder presents to them under continuous pressure and challenges. The breeder can afford to increase the coefficient of variation (CV) of traits in uniformly managed experiments due to lower experimental means. The $\mathrm{CV}$ is often described as an indication of the precision of an experiment. It is often used to discard experiments considered poor. However, it is important to be aware that the standard deviation is a more accurate indicator of experiment precision and higher CVs might provide, in certain cases, excellent quality information in low mean experiments. Figure 11 shows that a sustainable maize breeding program with winter nursery drought screening can develop drought tolerant cultivars to aid farmers reduce their irrigation needs in western North Dakota (ND) dry land regions. Within this goal, breeders can use side by side drought tolerance experiments in target environments arranged with the same experimental design within and across locations with the only difference that one experiment is under dry land conditions and the other one under irrigation. Experimental line ND09-229 was part of a series of short-season stable hybrids developed for western ND environments sold by cooperatives.

\section{Integrating pre-breeding with cultivar development: Releasing the next generation of cultivars}

As a cross-pollinated crop, maize breeding techniques are readily applicable to other species. Maize inbred lines are the confidential secret for hybrid providers who lead a competitive market worth billions of dollars. However, the emphasis on the inbred-hybrid system reduced population genetic improvement efforts to just a few maize breeding programs integrating pre-breeding with cultivar development. The EarlyGEM program (Carena 2002), the EarlyQPM and EarlyQPMF programs (Dong et al. 2012), stratified mass selection (Carena et al. 2008, Hallauer and Carena 2009), and recurrent selection programs (Carena and Wicks III 2006, Hallauer and Carena 2014), are some of the pre-breeding efforts that have integrated the creation and improvement of genetically broad-based synthetic varieties with the development of genetically diverse inbred lines and hybrids. Key factors for developing useful and unique cultivars were the adaptation of exotic germplasm and the maximization of its genetic improvement (Hallauer and Carena 2013) before inbred line and hybrid development. In addition, genetic divergence and reciprocal recurrent selection programs have 


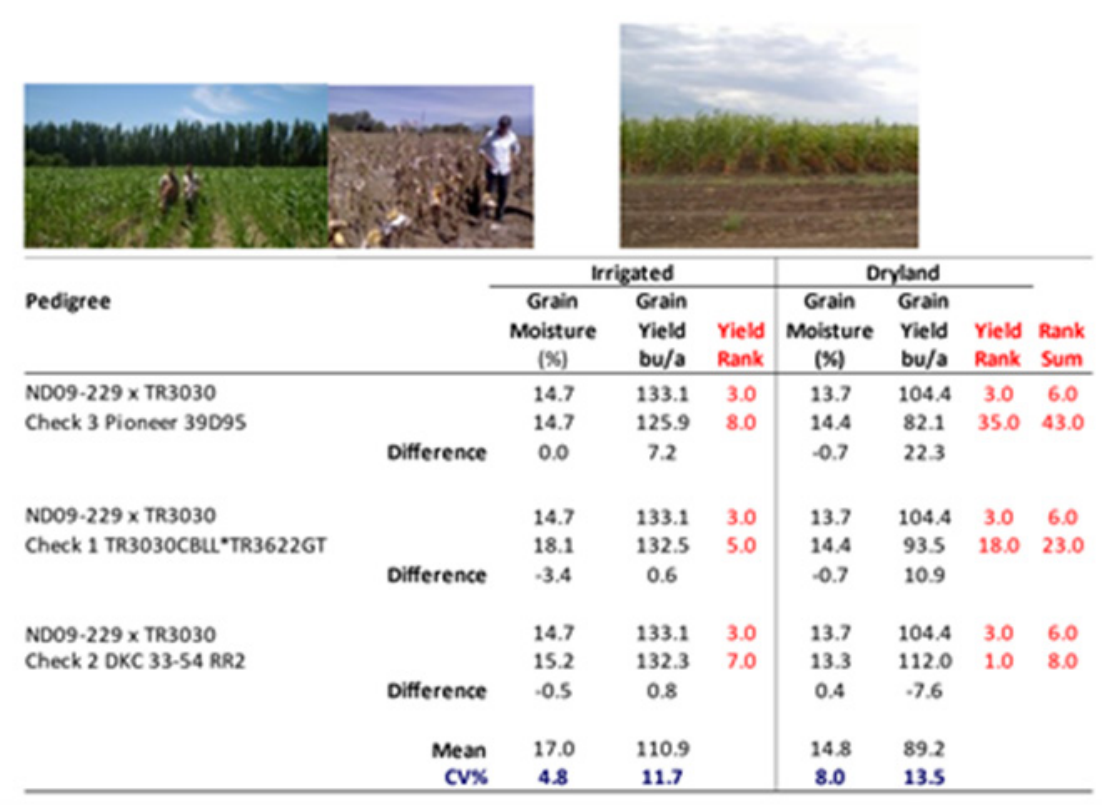

Figure 11. Maize experimental and commercial hybrids evaluated in both dry land and irrigated trials in Williston, ND (only ND09-229 experimental line screened in controlled winter nursery).

exploited the population-hybrid maize concept (Carena 2005).

Cultivars need to be ready to withstand any challenge presented to them so that, during development, cultivar germplasm sources are exposed to all possible stresses and have stable responses to changing climates. This is the reason why agronomists and farmers share similar concerns while being protective of their crops growing on farms, field days or experimental trials while breeders need to focus on exposing their broad genetic materials to a wide range of environmental conditions. Improved populations can be potential releases per se or as direct parents for population hybrids as well as future diverse sources of unique inbred lines for single-cross hybrids. New populations can be exclusively or non-exclusively distributed to public and private partners for population and population hybrid production and breeding purposes.

\section{Technology effects on traits and breeding techniques}

Choice of germplasm is important and so is the sampling and breeding environments utilized and how traits are targeted with breeding methodologies. Once a chosen germplasm demonstrates to yield useful desirable traits, it should be targeted with adequate breeding methodologies either old or new. Successful breeding technologies are not often the latest ones developed. Stratified mass selection, for instance, developed by Gardner (1961), can be the most costeffective technology for a particular situation. Traits that are genetically simple and easy to measure can be successfully screened in largest samples for fast genetic improvement at the lowest cost possible. With this technology tropical maize populations have successfully been adapted to lowa (Hallauer and Carena 2016) and North Dakota (Carena 2021a).

New breeding methodologies can facilitate breeders their work with quantitative traits in sustainable breeding programs (Figure 12). Molecular labs initially had the intention to assist breeders working with complex economically important traits but have targeted genetically simple traits instead, often not a challenge to breeders (Figure 11). Molecular markers have had a limiting effect on quantitative traits and reducing genotype by environment interactions (Sonnino et al. 2007) and changes in research emphasis have had a negative effect on sustainable breeding programs worldwide (Guimaraes et al. 2006).

Breeders should be challenged to develop cost-effective breeding methodologies for high throughput non-destructive screening of quantitative traits, especially those difficult to measure and largely influenced by the environment. Phenomic 
examples are growing. Maize breeding research on fast dry down (Yang et al. 2010) helped mitigate climate change by reducing the utilization of fossil fuels to dry grain on farm as northern U.S. maize often needs to be harvested at moisture levels too high for safe storage and must be artificially dried for storage and transport. Area under the dry down curve (AUDDC) was invented to better measure a genetically complex trait historically challenged by the environment. Sharma and Carena (2016) have developed BRACE to solve another difficult challenge. This method is non-destructive and high throughput for short-season drought tolerance involving visible brace root systems. Both methodologies needed a very low level of investment.

\section{CONCLUSIONS}

National research programs integrating pre-breeding

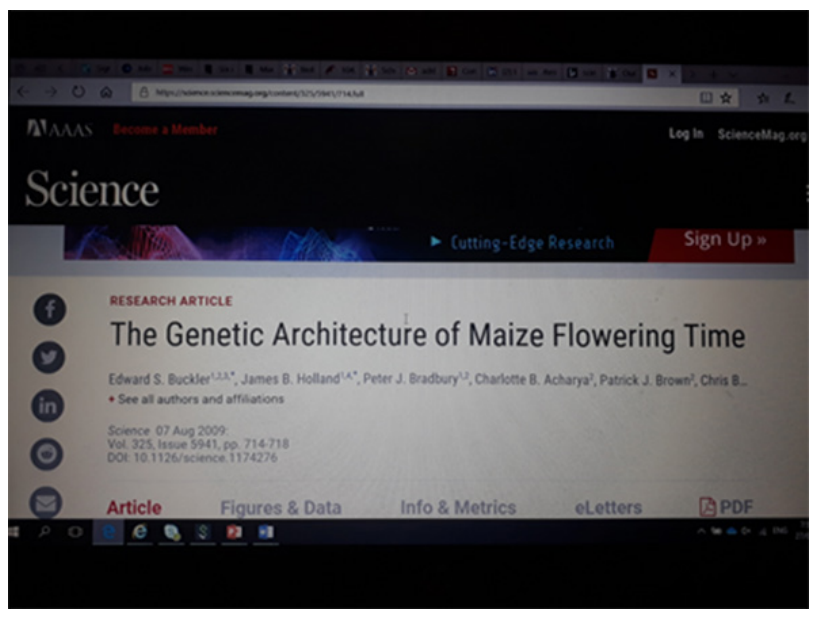

Figure 12. Targeting trait genetic complexity with technology. with genetically broad-based cultivar development efforts exploiting heterosis and strategic environments will be essential for plant and animal breeding programs developing the next generation of value-added products to the agrifood sector. Improved genetically broad-based germplasm will be the source to developing sustainable cultivars, offering unique genes not available in current genome sequences or industry products (Figure 6).

Agriculture is responsible for most of greenhouse gas emissions. There has been a significant increase in the utilization of irrigation, fertilizers, and pesticides. Sustainable breeders need to transform agriculture increasing sustainability and the value of agri-food products while enhancing biodiversity, adaptation to climate change, and protection of the environment.

One of the important challenges of the 21st century is to increase food supply and value with less production land, water, nutrients, and animals. Society is now more aware of the need for sustainable agri-food systems. But these systems need to be resilient and profitable if utilization of water and inputs are to be reduced.

Farmers are ready to adapt to climate change and comply with environmental regulations. However, while farmers are being asked to mitigate their environmental footprint, they are unable to access market cultivar options to address their sustainability challenges. There is a lack of awareness of this missing link between industry and farmers. The seed industry is responsible for providing sustainable options to farmers but has historically focused on developing cultivars with high fertilizer and water inputs under mild environments. In addition, the scientific community has not generated solutions that will lead to sustainable and climate-resilient cultivars being available to farmers. Commercial cultivars are genetically narrow and consequently vulnerable to emerging biotic and abiotic stresses that can cost millions of dollars to national economies, especially under the pressures of climate change with higher average temperatures expected. Prevention is essential to avoid major national economic losses. New sustainable cultivars are needed to make farms sustainable preventing genetic vulnerabilities to potential epidemics and significant economic impacts. Some of the solutions include the addition of useful germplasm diversity (Carena 2011, Carena 2013a) and the utilization of target stressful environments for faster genetic improvement (Carena 2013b, c).

Long-term breeding goals are essential for the future sustainability of production not only in current production areas but also in areas where maize production is headed (Carena 2013c). Pre-breeding results have shown that germplasm carrying unique genes can break environmental margins for maize production (Carena 2011). Biodiversity will be essential for climate change adaptation and economic stability. There is a need for sustainable breeding projects that will meet present and future demands of superior cultivars tolerant to climate changes (Carena 2011). Several quantitative traits are still in need of breeding methodologies that could follow the examples described. The scientific community will significantly advance existing knowledge if better targeting of traits with cost and efficient new phenotyping breeding ideas and technologies are followed focusing on data needed rather than collecting all data possible. Breeders will need to increase the genetic diversity of species applying the experience of population improvement programs from other species. 
Choice of germplasm will continue to be priority over novel technologies. Improvement of adapted germplasm requires maximum accuracy increasing trait heritability with best experimental techniques in multiple environments minimizing selection among individuals for genetically complex traits. Progeny testing efforts should be increased complemented with targeted used of technologies and data minimizing GxE interactions with use of strategic environments to maximize productivity under climate change and low environmental footprint. Long-term systematic breeding goals will be essential.

Most important will be the training of the next generation of sustainable breeders. There has, during the past 30 years, been a serious erosion of plant and animal breeders at universities to educate and train future scientists enhancing germplasm and developing new genetically broad-based products for the next generation of farmers. Because of the rapid expansion within the commercial sector, a critical mass of sustainable breeders is essential to meet future demands for increased sustainable productivity and value of agri-food products ahead of climate change.

\section{REFERENCES}

Bari MAA, Pereira M and Carena MJ (2016) Identification of heterotic patterns between expired proprietary, NDSU, and current industry short-season maize (Zea mays L.) inbred lines. Crop Breeding and Applied Biotechnology 16: 274-281.

Carena MJ (2003) ‘EarlyGEM’: Incorporating GEM elite lines in early maize. In GEM 2003 Public cooperator rep. germplasm enhancement of maize, Ames, IA. Available at <http://www.public.iastate.edu/ usdagem/Public_Reports/GEM_PR_03.htm>. Accessed Dec. 2003.

Carena MJ (2005) Maize commercial hybrids compared to improved population hybrids for grain yield and agronomic performance. Euphytica 141: 201-208.

Carena MJ (2011) Germplasm enhancement for adaptation to climate changes. Crop Breeding and Applied Biotechnology 11: 56-65.

Carena MJ (2013a) Challenges and opportunities for developing maize cultivars in the public sector. Euphytica 191: 165-171.

Carena MJ (2013b) Developing cold and drought tolerant short-season maize products for fuel and feed utilization. Crop Breeding and Applied Biotechnology 13: 1-8.

Carena MJ (2013c) Developing the next generation of diverse and healthier maize cultivars tolerant to climate changes. Euphytica 190: $471-479$.

Carena MJ (2017) Developing maize breeding methods and cultivars to meet the challenge of climate change. In Watson D (ed) Achieving sustainable cultivation of maize vol 1: From improved varieties to local applications. Burleigh Dodds Science Publishing, London, p. 87-113.

Carena MJ (2021a) The EarlyTrop maize program: Adaptation of $100 \%$ tropical maize to North Dakota short-seasons. Functional Plant Breeding Journal 3: 11-21.

Carena MJ (2021b) Who will develop the next generation of forages not addicted to nitrogen and water? Addressing the missing link between industry and farmers. Journal of New Zealand Animal Production (in press).

Carena MJ (2021c) A case for moving forage germplasm southward. Journal of New Zealand Grasslands (in press).
Carena MJ (2021d) Adaptation of maize breeding techniques to maximize genetic gain and phenomics innovations in the New Zealand primary industry. Genes Special Issue (in press).

Carena MJ and Cross HZ (2003) Plant density and maize germplasm improvement in the Northern Corn Belt. Maydica 48: 105-111.

Carena MJ and Dong N (2017) The EarlyQPM program: Developing the next generation of healthier maize products. Euphytica 213: 150.

Carena MJ and Hallauer AR (2001a) Response to inbred progeny recurrent selection in Leaming and Midland Yellow Dent populations. Maydica 46: 1-10.

Carena MJ and Hallauer AR (2001b) Expression of heterosis in Leaming and Midland Yellow Dent populations. Journal of the lowa Academy of Science 108: 73-78.

Carena MJ and Sharma S (2016) Registration of five Short-Season Stiff Stalk (SS) EarlyGEM maize germplasms. Journal of Plant Registrations 10: 301-308.

Carena MJ and Wicks III ZW (2006) Maize early maturing hybrids: An exploitation of U.S. temperate public genetic diversity in reserve. Maydica 51: 201-208.

Carena MJ, Bergman G, Riveland N, Eriksmoen E and Halvorson M (2009b) Breeding maize for higher yield and quality under drought stress. Maydica 54: 287-296.

Carena MJ, Eno C and Wanner DW (2008) Registration of NDBS11(FR-M) C3, NDBS1011, and NDBSK(HI-M)C3 maize germplasms. Journal of Plant Registrations 2: 132-136.

Carena MJ, Pollak L, Salhuana W and Denuc M (2009a) Development of unique lines for early-maturing hybrids: Moving GEM germplasm northward and westward. Euphytica 170: 87-97.

Davies N, Carena MJ and Rolston P (2020) Adapting forages to climate changes and lower environmental footprint. Agronomy New Zealand 50: 1-13.

Dong N, Laude T and Carena MJ (2012) The NDSU EarlyQPM program: The next generation of healthier short-season products. In 2012 Corn utilization and technology conference. National Corn Growers Association, Indianapolis.

Duvick DN (1984) Genetic diversity in major farm crops on the farm and in reserve. Economy Botany 38: 161-178. 


\section{MJ Carena}

Edwards J (2016) Genotype by environment interaction for plant density response in maize. Crop Science 56: 1493-1505.

Gardner CO (1961) An evaluation of effects of mass selection and seed irradiation with thermal neutrons on yield of corn. Crop Science 1: 241-245.

Goodman MM (1999) Broadening the genetic diversity in maize breeding by use of exotic germplasm. In Coors JG and Pandey S (eds) Genetics and exploitation of heterosis in crops. ASA, CSSA, and SSSA, Madison, p. 139-148.

Guimaraes E, Kueneman E and Carena MJ (2006) Assessment of national plant breeding and biotechnology capacity in Africa and recommendations for future capacity building. Horticulture Science 41: 50-52.

Hallauer AR (1999) Conversion of tropical germplasm for temperate area use. Illinois Corn Breeders' School 35: 20-36.

Hallauer AR and Carena MJ (2009) Maize breeding. In Carena MJ (ed) Handbook of plant breeding: Cereals. Springer, New York, p. 3-98.

Hallauer AR and Carena MJ (2013) Recurrent selection in maize. Maydica 57: 266-283.

Hallauer AR and Carena MJ (2014) Adaptation of tropical maize germplasm to temperate environments. Euphytica 196: 1-11.

Hallauer AR and Carena MJ (2016) Registration of BS39 maize germplasm. Journal Plant Registrations 10: 296-300.

Hallauer AR, Carena MJ and Miranda Filho JB (2010) Quantitative genetics in maize breeding. $3^{\text {rd }}$ edn, Springer, New York, 664p.

Hyrkas A and Carena MJ (2005) Response to long-term selection in early maturing maize synthetic varieties. Euphytica 143: 43-49.

Laude TP and Carena MJ (2015) Genetic diversity and heterotic grouping of tropical and temperate maize populations adapted to the northern U.S. Corn Belt. Euphytica 204: 661-677.

Mansfield BD and Mumm RH (2014) Survey of plant density tolerance in
US maize germplasm. Crop Science 54: 157-173.

Pollak LM (2003) The history and success of the public-private project on germplasm enhancement of maize (GEM). Advances in Agronomy 78: 45-87.

Sevilla R and Salhuana W (1997) General description of the plan and execution of Latin American Maize Project (LAMP). In Salhuana W, Sevilla R and Eberhart SA (eds) LAMP final report 1997. USDA, Fort Collins, p. 1-36.

Sezegen B and Carena MJ (2009) Divergent recurrent selection for cold tolerance in two improved maize populations. Euphytica 167: 237244.

Sharma S and Carena MJ (2012) NDSU EarlyGEM: Increasing the genetic diversity of northern U.S. hybrids through the development of unique exotic elite lines. Maydica 57: 34-42.

Sharma S and Carena MJ (2016) BRACE: A method for high throughput maize phenotyping of root traits for short-season drought tolerance. Crop Science 6: 2996-3004.

Sonnino A, Carena MJ, Guimaraes EP, Baumung R, Pilling D and Rischkowsky B (2007) An assessment of the use of molecular markers in developing countries. In Guimaraes EP, Ruane J, Scherf BD, Sonino A and Dargie JD (eds) Marker-assisted selection: Current status and future perspectives in crops, livestock, forestry, and fish. Food and Agriculture Organization of the United Nations, Rome, p. 15-26.

Tollenaar M, Ahmadzadeh A and Lee EA (2004) Physiological basis of heterosis for grain yield in maize. Crop Science 44: 2086-2094.

Troyer AF and Rosenbrook RW (1983) Utility of higher plant densities for corn performance testing. Crop Science 23: 863-867.

Wackernagel M and Rees W (1995) Our ecological footprint: Reducing human impact on the earth. New Society Publishers, Gabriola Island, 176p.

Yang J, Carena MJ and Uphaus J (2010) AUDDC: A new method to evaluate rate of dry down in maize. Crop Science 50: 1-8. 